1 Harvard Department of the History of Science, Cambridge, MA, USA

2 Maurice Young Centre for Applied Ethics, School of Population and Public Health, University of British

Columbia, Vancouver, BC, Canada

3 Department of Political Science, University of British Columbia Vancouver, BC, Canada

4 Boston University, Boston, MA, USA

Correspondence to: I Bavli itaibavli@fas.harvard.edu

Cite this as: BMJ 2020;371:m4074 http://dx.doi.org/10.1136/bmj.m4074 Published: 02 November 2020

\title{
Harms of public health interventions against covid-19 must not be ignored
}

\section{The harmful consequences of public health choices should be explicitly considered and transparently reported to limit their damage, say Itai Bavli and colleagues}

Itai Bavli, ${ }^{1,2}$ Brent Sutton, ${ }^{3}$ Sandro Galea ${ }^{4}$

The SARS-CoV-2 pandemic has posed an unprecedented challenge for governments. Questions regarding the most effective interventions to reduce the spread of the virus-for example, more testing, requirements to wear face masks, and stricter and longer lockdowns-become widely discussed in the popular and scientific press, informed largely by models that aimed to predict the health benefits of proposed interventions. Central to all these studies is recognition that inaction, or delayed action, will put millions of people unnecessarily at risk of serious illness or death.

However, interventions to limit the spread of the coronavirus also carry negative health effects, which have yet to be considered systematically. Despite increasing evidence on the unintended, adverse effects of public health interventions such as social distancing and lockdown measures, there are few signs that policy decisions are being informed by a serious assessment and weighing of their harms on health. Instead, much of the discussion has become politicised, especially in the US, where President Trump's provocative statements sparked debates along party lines about the necessity for policies to control covid-19. This politicisation, often fuelled by misinformation, has distracted from a much needed dispassionate discussion on the harms and benefits of potential public health measures against covid-19.

\section{Collateral damage}

The harmful consequences of public health interventions can be direct or indirect-for example, psychological harms, equity harms, group and social harms, opportunity harms, and inequalities in intervention benefits. ${ }^{12}$ These interventions can increase the adverse outcomes they seek to prevent or affect other health outcomes. ${ }^{2-4}$ Policy makers, acting to protect public health, need to weigh the possible side effects when deciding on, implementing, and evaluating specific public health interventions. ${ }^{1}$

Public policy efforts that have been implemented to deal with the covid-19 pandemic have been caught in a political maelstrom precisely because these efforts, in their first iteration, did not consider the potential negative consequences. Although policies to bring about mass social distancing may have slowed viral spread, they also brought about unprecedented levels of unemployment that led to justifiable resistance from some sectors. Had these policy efforts explicitly considered these consequences from the start-and social distancing has long been an element of planning for a severe pandemic-this would have obviated some of the political backlash, leading to more uniform and more effective implementation of these policies.

We offer three areas of harm that should become part of all efforts to evaluate, assess, and respond to the harmful consequences of strategies to contain SARS-CoV-2.

\section{Excess deaths and inequalities arising from economic damage}

The underlying assumption of any public health intervention is that it will enable more people to live longer and healthier. Application of the physicians' oath "first do no harm" to public health means that positive outcomes of public health interventions need to outweigh any negative effects. Therefore, the task for public health is not simply to consider the lives that may be saved by policy efforts to limit viral spread, but more importantly, to consider the total number of lives saved and lost as a result of the epidemic and responses to it.

Evidence is conflicting about the effect of rising unemployment during economic recessions on overall population health. ${ }^{5}$ Studies in high income countries relying on aggregate data show death rates tend to fall as unemployment rates increase, although individual level studies often find the opposite. ${ }^{6}$ The reduced deaths are thought to be related to fewer cardiovascular events and motor vehicle incidents. ${ }^{7}$

Research in low and middle income countries, however, has found higher mortality rates during economic recessions. ${ }^{8} 9$ Furthermore, this research is population based and does not account for heterogeneity in populations. The health consequences of economic downturns are likely to be felt more acutely among already socioeconomically vulnerable populations, suggesting that economic shocks will widen health divides. ${ }^{10}$

The economic shock caused by efforts to contain SARS-CoV-2 is larger than that arising from the 2007-09 financial crisis. It is therefore critical that models that aim to understand the effect of covid-19 policies on health also consider lives lost as a result of the economic consequences of the response to the pandemic to avoid portraying a false choice between the economy and health.

Findings from past economic recessions suggest that harms caused by economic shutdowns vary by a country's level of economic development, with more deaths expected in middle and low income countries. Governments should therefore use models to measure 
excess deaths that are sensitive to a particular country's economic circumstances. This might lead to poorer countries considering more targeted interventions that avoid wholesale shutdowns of an entire economy. The severity of the economic shock caused by the measures to contain the virus strongly suggests that we need to reassess the expected death rate across all countries.

\section{Negative health effects}

Restrictive measures on social mobility and the economy are associated with adverse health outcomes in both the short term and the long term. Short term health effects occur during or shortly after interventions are put in place. For example, in a review of the evidence of psychological harms of quarantines, Brooks and colleagues ${ }^{11}$ show that such measures increased anger, confusion, and symptoms of post-traumatic stress disorder (PTSD). School closures, which require parents (or relatives) to stay at home, can also lead to adverse health effects-for example, if staff shortages from healthcare workers staying at home to look after their children reduce the quality of care. ${ }^{12}$

Lockdowns can also cause long term health harms, such as from delayed treatment and investigations. Delays in the diagnosis and treatment of various types of cancer, for example, can allow progression of cancer and affect patients' survival. A three month delay to surgery is estimated to cause more than 4700 deaths a year in the UK. ${ }^{13}$ In the US, delays in screening and treatment are estimated to cause 250 ooo additional preventable deaths of cancer patients each year. ${ }^{14}$ Furthermore, a sharp decrease in the number of admissions for acute coronary syndromes and emergency coronary procedures has been observed since the start of the pandemic in the US ${ }^{15}$ and Europe. ${ }^{16}$ In England, the weekly number of hospital admissions for coronary syndromes fell by $40 \%$ between mid-February and the end of March 2020. Fear of exposure to the virus stopped many patients from attending hospital, putting them at increased risk of long term complications of myocardial infarction. ${ }^{17}$

Including the various adverse effects of social isolation and economic lockdowns can help weigh these harms alongside the immediate harms of the virus. Some immediate effects are known and are already being mitigated. For example, providing telephone and video consultations to those experiencing psychological harms from physical distancing can lessen their distress. ${ }^{18}$ The long term effects of lockdowns are harder to predict, though they may be more serious than short term harms. Modelling should allow decision makers to identify these potential harms and balance them against the benefits before public health decisions are made.

\section{Effect on vulnerable populations.}

Lockdowns and social isolation measures affect some populations more than others, and the effects extend well beyond mortality.
Disadvantaged low income communities and people with mental health and addiction problems are more likely to be adversely harmed by social distancing measures. ${ }^{19}$ This matters because it is these same groups that are most vulnerable to the virus. A US Centers for Disease Control and Prevention study ${ }^{20}$ found that 33\% of patients admitted to hospital with covid-19 were black-a disproportional number in the population. This overrepresentation of African Americans is due to structural factors such as health disparities, more limited access to healthcare services, and crowded living conditions. ${ }^{21}$

Models to identify and protect vulnerable populations at higher risk of dying from covid-19 are valuable, but it is equally important to identify and assist populations most vulnerable to lockdown measures. For example, low wage workers who depend on their daily income to survive are at the highest risk of health problems arising from economic stagnation. This problem is even more severe in low income countries. Reports from India, for example, show that the March lockdown risked starvation of migrant workers, who were forced to return to their homes and leave their jobs, as well as spreading the virus to their home villages. ${ }^{22}$

Social distancing may also negatively affect people with addiction disorders. In North America, which is in the midst of an opioid epidemic, limited access to clinics for opioid use disorders because of physical distancing measures, for example, may inadvertently exacerbate drug diversion and opioid overdoses. ${ }^{19}$ Ontario and British Columbia (Canada) have seen a spike in overdose deaths since the lockdown started. ${ }^{23}$

Orders to stay at home or isolate can also increase child abuse and domestic violence rates. Reports from Hubei (China), France, Argentina, Singapore, and several US cities show a substantial increase in domestic violence during the lockdowns. ${ }^{24}$

The health effects of isolation measures on different populations will vary depending on a country's level of economic development, the comprehensiveness of government safety nets, and pre-existing health and disparities among its population. For some communities, such as those with low incomes and those who struggle with addiction disorders, the unintended consequences of lockdown measures are severe and should not be overlooked. Modelling should therefore identify the most vulnerable populations in a given country (and the mechanisms of harm) and assess potential harm when deciding on the appropriate public health intervention. A public accounting of the expected harms needs to be incorporated into the decision making framework. If the harms exceed the benefits, other interventions should be considered or strategies should be developed to lessen their impact (table 1). 
Table 1 | Recommendations for comprehensive interventions to minimise harm from covid-19

\begin{tabular}{|c|c|c|c|}
\hline Health outcomes & Factors & Weigh and assess & Act \\
\hline \multirow[t]{2}{*}{ Mortality rate } & Level of economic development & $\begin{array}{l}\text { Effect of interventions on death rates in low, } \\
\text { medium, and high income countries }\end{array}$ & \multirow{2}{*}{$\begin{array}{l}\text { Tailor interventions to level of economic } \\
\text { development or with different assets (eg, low } \\
\text { income countries should consider alternatives } \\
\text { to economy-wide lockdowns) }\end{array}$} \\
\hline & Socioeconomic status & $\begin{array}{l}\text { Effect on people with different socioeconomic } \\
\text { status }\end{array}$ & \\
\hline Short and long term health & Non-mortality health outcomes & $\begin{array}{l}\text { Effect of interventions on non-mortality health } \\
\text { outcomes }\end{array}$ & $\begin{array}{l}\text { Assess harms against benefits before deciding } \\
\text { on new measures and transparently report } \\
\text { them. Develop strategies to mitigate or avoid } \\
\text { unintended harms from interventions (eg, } \\
\text { maintain essential medical tests, examinations, } \\
\text { and immunisations during lockdowns) }\end{array}$ \\
\hline Vulnerable communities & Populations most susceptible to interventions & $\begin{array}{l}\text { Effect of interventions on the economic and } \\
\text { health outcomes of vulnerable communities }\end{array}$ & $\begin{array}{l}\text { Transparently report the expected harm for } \\
\text { vulnerable populations and incorporate these } \\
\text { considerations when deciding on and evaluating } \\
\text { new public health policies. Develop strategies } \\
\text { to mitigate or avoid harms caused to } \\
\text { vulnerable communities from interventions (eg, } \\
\text { maintain access to opioid use disorders clinics } \\
\text { during lockdowns) }\end{array}$ \\
\hline
\end{tabular}

\section{Looking ahead: call for collaborative action}

The coronavirus pandemic is far from over. Many countries are already reeling from the effects of the pandemic response as well as trying to cope with additional waves of dangerous infection rates. Governments will have to make difficult decisions that rely on uncertain and changing data regarding the most effective approaches to contain the pandemic. Although the evidence on the adverse consequences of measures to control covid-19 continues to grow, ${ }^{1325-28}$ there remains a paucity of any such voices in the public and decision making conversation, which seems to convey a dominant narrative of pandemic mitigation at all costs. This is perhaps a reflection of the challenge of the moment, but we must adopt a more nuanced approach to understanding the pros and cons of different approaches.

A "zero covid" goal is neither realistic nor sustainable for most countries. Instead, public health needs to increase its investment into assessing the harms of policy options from different perspectives and to explicitly consider and transparently report the harmful consequences of public choices when deciding on and evaluating public health strategies to combat SARS-CoV-2. Epidemiologists, health economists, social scientists, psychologists, historians, ethicists, among others, must all contribute to these efforts and assist governments in making informed decisions-improving and protecting the health of all communities.

Key messages

- Public health policies to combat SARS-CoV-2 mostly rely on models designed to predict their benefits

- These models often ignore potential harms that arise from these policies

- The short and long term adverse health effects of physical distancing measures, including unnecessary deaths, need to be evaluated and vulnerable populations identified

- Economic effects cannot be separated from health effects, and interventions designed to control covid-19 need to take account of unintended consequences

Contributors and sources: IB's scholarship is at the intersection of the harmful effects of public health interventions and ethics. BS works on comparative political economy, with a focus on international financial institutions and markets. Before 2011, he was a senior partner with an investment management firm. SG works on the social causes of health and the science of population health. All authors were involved in the design, research, write-up, and reporting stages of this paper. IB is the guarantor.
Competing interests: We have read and understood BMJ policy on competing interests and have no relevant interests to declare.

Provenance and peer review: Not commissioned; externally peer reviewed.

We thank Peter Berman for his valuable comments and suggestions.

Lorenc T, Oliver K. Adverse effects of public health interventions: a conceptual framework. J Epidemiol Community Health2014;68:288-90. doi: 10.1136/jech-2013-203118 pmid: 24336237

2 Bonell C, Jamal F, Melendez-Torres GJ, Cummins S. 'Dark logic': theorising the harmful consequences of public health interventions. J Epidemiol Community Health 2015;69:95-8.pmid: 25403381

3 Carlin JB, Taylor P, Nolan T. School based bicycle safety education and bicycle injuries in children: a case-control study. Inj Prev1998;4:22-7.pmid: 9595327

4 Shvarts S, Sevo G, Tasic M, Shani M, Sadetzki S. The tinea capitis campaign in Serbia in the 1950s. Lancet Infect Dis 2010;10:571-6.pmid: 20670904

5 Burgard SA, Ailshire JA, Kalousova L. The Great Recession and health: people, populations, and disparities. Ann Am Acad Pol Soc Sci2013;650:194-213.

6 Gerdtham UG, Ruhm CJ. Deaths rise in good economic times: evidence from the OECD. Econ Hum Biol 2006;4:298-316.pmid: 16713407

7 Strumpf EC, Charters TJ, Harper S, Nandi A. Did the Great Recession affect mortality rates in the metropolitan United States? Effects on mortality by age, gender and cause of death. Soc Sci Med 2017;189:11-6. doi: 10.1016/j.socscimed.2017.07.016 pmid: 28772108

8 Hone T, Mirelman AJ, Rasella D, etal. Effect of economic recession and impact of health and social protection expenditures on adult mortality: a longitudinal analysis of 5565 Brazilian municipalities. Lancet Glob Health 2019;7:e1575-83. doi: 10.1016/S2214-109X(19)30409-7 pmid: 31607469

9 Gonzalez F, Quast T. Mortality and business cycles by level of development: evidence from Mexico. Soc Sci Med2010;71:2066-73. doi: 10.1016/j.socscimed.2010.09.047 pmid: 21074307

10 Kawohl W, Nordt C. COVID-19, unemployment, and suicide. Lancet Psychiatry 2020;7:389-90. doi: 10.1016/S2215-0366(20)30141-3 pmid: 32353269

11 Brooks SK, Webster RK, Smith LE, etal. The psychological impact of quarantine and how to reduce it: rapid review of the evidence. Lancet 2020;395:912-20. doi: 10.1016/S0140-6736(20)30460-8 pmid: 32112714

12 Bayham J, Fenichel EP. Impact of school closures for COVID-19 on the US health-care workforce and net mortality: a modelling study. Lancet Public Health 2020;5:e271-8. doi: 10.1016/S2468-2667(20)30082-7 pmid: 32251626

13 Sud A, Jones ME, Broggio J, etal. Collateral damage: the impact on outcomes from cancer surgery of the COVID-19 pandemic. Ann Oncol 2020;31:1065-74. doi: 10.1016/j.annonc.2020.05.009 pmid: 32442581

14 Mihaljevic T, Farrugia G. How many more will die from fear of the coronavirus? New York Times 2020 Jun 9. https://www.nytimes.com/2020/06/09/opinion/coronavirus-hospitals-deaths.html

15 Solomon MD, McNulty EJ, Rana JS, etal. The covid-19 pandemic and the incidence of acute myocardial infarction. N Engl J Med 2020;383:691-3. doi: 10.1056/NEJMc2015630 pmid: 32427432

16 De Filippo O, D’Ascenzo F, Angelini F, etal. Reduced rate of hospital admissions for ACS during Covid-19 outbreak in northern Italy. N Engl J Med 2020;383:88-9. doi: 10.1056/NEJMc2009166 pmid: 32343497

17 Mafham MM, Spata E, Goldacre R, etal. Covid-19 pandemic and admission rates for and management of acute coronary syndromes in England. Lancet 2020;396:381-9. doi: 10.1016/S0140-6736(20)31356-8 pmid: 32679111 
18 Razai MS, Oakeshott P, Kankam H, Galea S, Stokes-Lampard H. Mitigating the psychological effects of social isolation during the covid-19 pandemic. BMJ 2020;369:m1904.

doi: 10.1136/bmj.m1904 pmid: 32439691

19 Marsden J, Darke S, Hall W, etal. Mitigating and learning from the impact of COVID-19 infection on addictive disorders. Addiction 2020;115:1007-10. doi: 10.1111/add.15080 pmid: 32250482

20 CDC. Covid-19 in racial and ethnic minority groups. 2020 https://www.cdc.gov/coronavirus/2019ncov/need-extra-precautions/racial-ethnic-minorities.html

21 Hooper MW, Nápoles AM, Pérez-Stable EJ. Covid-19 and racial/ethnic disparities. JAMA 2020;323:2466-7. doi:10.1001/jama.2020.8598.

22 Sharma V, Sinha S, Abhijay J, Neha L. Coronavirus: massive evacuation operation on as huge mass of migrants heads out of Delhi. Times of India 2020 Mar 29. https://timesofindia.indiatimes.com/india/coronavirus-massive-evacuation-operation-on-as-huge-mass-of-migrants-headsout-of-delhi/articleshow/74868719.cms

23 Public Health Agency of Canada. Statement from the chief public health officer of Canada on Covid-19, 29 May. 2020. https://www.canada.ca/en/public-health/news/2020/05/statementfrom-the-chief-public-health-officer-of-canada-on-covid-198.html

24 Boserup B, McKenney M, Elkbuli A. Alarming trends in US domestic violence during the COVID-19 pandemic. Am J Emerg Med 2020;S0735-6757(20)30307-7, in press.pmid: 32402499

25 Roberton T, Carter ED, Chou VB, etal. Early estimates of the indirect effects of the COVID-19 pandemic on maternal and child mortality in low-income and middle-income countries: a modelling study. Lancet Glob Health2020;8:e901-8. doi: 10.1016/S2214-109X(20)30229-1 pmid: 32405459

26 Jewell BL, Mudimu E, Stover J, etalHIV Modelling Consortium. Potential effects of disruption to HIV programmes in sub-Saharan Africa caused by COVID-19: results from multiple mathematical models. Lancet HIV 2020;7:e629-40. doi: 10.1016/S2352-3018(20)30211-3 pmid: 32771089

27 World Health Organization. The potential impact of health service disruptions on the burden of malaria: a modelling analysis for countries in sub-Saharan Africa. 2020.

https://www.who.int/publications-detail/the-potential-impact-of-health-service-disruptions-onthe-burden-of-malaria

28 Forchini G, Løchen A, Hallett T, etal. Report 28: excess non-covid-19 deaths in England and Wales between 29th February and 5th June 2020. Imperial College London, 2020.

This article is made freely available for use in accordance with BMJ's website terms and conditions for the duration of the covid-19 pandemic or until otherwise determined by BMJ. You may use, download and print the article for any lawful, non-commercial purpose (including text and data mining) provided that all copyright notices and trade marks are retained. 